\title{
A Solar Powered Liquid-Desiccant Cooling System for Greenhouses
}

\author{
G. Lychnos and P. A. Davies* \\ School of Engineering and Applied Science, Aston University, Birmingham, B4 7ET, UK \\ *Corresponding author p.a.davies@aston.ac.uk,
}

Keywords: greenhouse cooling, solar energy, liquid desiccant

\begin{abstract}
Liquid desiccant systems are of potential interest as a means of cooling greenhouses to temperatures below those achieved by conventional means. However, only very little work has been done on this technology with previous workers focussing on the cooling of human dwellings using expensive desiccants such as lithium salts. In this study we are designing a system for greenhouse cooling based on magnesium chloride desiccant which is an abundant and non-toxic substance. Magnesium chloride is found in seawater, for example, and is a by-product from solar salt works. We have carried out a detailed experimental study of the relevant properties of magnesium rich solutions. In addition we have constructed a test rig that includes the main components of the cooling system, namely a dehumidifier and solar regenerator. The dehumidifier is a cross-flow device that consists of a structured packing made of corrugated cellulose paper sheets with different flute angles and embedded cooling tubes. The regenerator is of the open type with insulated backing and fabric covering to spread the flow of desiccant solution. Alongside these experiments we are developing a mathematical model in gPROMS ${ }^{\circledR}$ that combines and simulates the heat and mass transfer processes in these components. The model can be applied to various geographical locations. Here we report predictions for Havana (Cuba) and Manila (Philippines), where we find that average wet-bulb temperatures can be lowered by 2.2 and $3^{\circ} \mathrm{C}$ respectively during the month of May.
\end{abstract}

\section{INTRODUCTION}

The extension of the optimum growing season for crop cultivation in greenhouses, located in hot countries, has been suggested by other researchers as a way of decreasing food imports. This can be achieved by reducing the high temperatures induced inside the greenhouses during summer with a cooling system that is less energy intensive and more effective than the conventional ones already used e.g. evaporative pad and fan ventilation systems.

Liquid desiccant cooling technology has been investigated extensively focusing on applications such as cooling of human dwellings, commercial buildings, hospitals (Jain et al., 2000; Oliveira et al., 2000; Dai et al., 2001; Gommed and Grossman, 2004; Mei and Dai, 2008). The desiccants utilised are lithium salts ( $\mathrm{LiCl}, \mathrm{LiBr}$ ), calcium chloride (or mixtures of $\mathrm{LiCl}$ and $\mathrm{CaCl}_{2}$ ) and tri-ethylene glycol. Although magnesium chloride is not as hygroscopic as the lithium salts or their mixtures, it is less expensive and non-toxic. Therefore it could be used potentially as a liquid desiccant in solar refrigeration systems providing low grade cooling in particular systems for cooling greenhouses in hot and humid climates. Davies (2005) theoretically demonstrated a solar powered liquid desiccant cooling system that lowers summer maximum summer temperatures by $5^{\circ} \mathrm{C}$. The use of bitterns (brines rich in $\mathrm{Mg}^{+2}$ ) as the liquid desiccant in such a system was 
proposed by Davies and Knowles (2006). The feasibility of the system has to be investigated thoroughly at the laboratory scale by conducting experiments. Thus we constructed a rig which consists of a dehumidifier and a solar regenerator. We have also developed mathematical models to simulate the processes of dehumidification and regeneration.

In this study, we report on the progress made in developing mathematical models that combine and simulate the mass and heat transfer processes that take place in the system and the preliminary experimental results, along with predictions of the efficacy for different geographic locations.

\section{METHODS AND EXPERIMENTAL PROCEDURES}

A schematic description of the liquid cooling system constructed in lab is shown in Fig.1. It consists of the following components: a) the air dehumidifier consisting of the packed column and cooling tubes, b) the humidifier and heater of the air at the inlet, c) a fan that draws the air out of the dehumidifier, d) two air sampling tubes for measuring the dry bulb and wet bulb temperatures of the incoming humid air and the out coming dehumidified air, e) the liquid desiccant regenerator, f) a peristaltic pump for circulating the liquid desiccant.

The packed column is constructed with four separate cellulose structured pads each one sized $0.1 \times 0.1 \times 0.3 \mathrm{~m}$. Each pad consists of specially impregnated and corrugated cellulose paper sheets with different flute angles, one steep (60 deg) and one flat (30 deg) that have been bonded together (CELdek® 7090-15). Fifty copper tubes (15mm OD) are embedded into the packed column providing cooling (tap water is used as the cooling fluid). The strong magnesium chloride solution flows through two manifolds from the top to bottom inside the column, wetting the cellulose structured packing. As the humid air passes horizontally (ie. in cross-flow configuration) through the column, moisture is removed as the water vapour is absorbed by the liquid desiccant. The weak magnesium chloride solution is collected at the bottom of the column inside a tank and by gravity flows freely through a tube to the regenerator-manifold.

The regenerator is an open type flat plate regenerator (no glazing) set with an inclination of 2.5 degrees to the horizontal. The regenerator surface is covered by a $5 \mathrm{~mm}$ black neoprene foam sheet and a woven black mulch sheet (polythene) on the top for better dispersion of the solution on the surface. The weak magnesium chloride solution is regenerated by flowing as a fluid film in contact with the ambient air. Under real conditions the solution will be heated by the sun. Therefore in lab we had to construct a solar simulator which is an array of 90 bulbs $(4.5 \mathrm{~kW}$ power supply) arranged in a triangular pattern. Each bulb was an EIKO Q50MR16 Solux bulb, 50W, $4700 \mathrm{~K}$ (daylight simulation bulb), $36 \mathrm{deg}$. dichroic spot. They were arranged with a pitch of $109 \mathrm{~mm}$ between them. The solar simulator provides the necessary heat to drive the water off the solution. The regenerated liquid desiccant is collected in a tank and from there the peristaltic pump returns it to the packed column.

The temperatures are measured using platinum resistance detectors (PT104 Pico Technology, UK) and the readings are scanned and recorded by the PicoLog data logging software. gPROMS $®$ software is used to model the processes of heat and mass transfer taking place inside the system. gPROMS $®$ was chosen as an equation-oriented modelling system used for building, validating and executing first-principles models within a flowsheeting framework. This software will be used to model the overall solar liquid 
cooling system which incorporates secondary processes such as the pumping process of the liquid desiccant and the cooling tubes of the packed column.

\section{RESULTS AND DISCUSSION}

\section{Theory}

The heat and mass transfer processes in liquid desiccant cooling systems occurring in structured and random packed columns have been investigated by several authors (Stevens et al., 1989; Al-Farayedhi et al., 2002; Gandhidasan, 2004; Liu et al., 2007a; Liu et al., 2007b; Yin and Zhang, 2008). The mathematical model developed here is based on the analysis done by Ying and Zhang (2008) which is an extension of Stevens et al (1989) model. The structured packed column is considered as a control volume. Taking a differential control volume (Fig. 2) the following equations can be derived.

For the heat transfer between the air and the liquid:

$$
G_{a} \cdot C_{P a} \cdot d T_{a}=h_{C} \cdot\left(T_{s}-T_{a}\right) \cdot a_{w} \cdot L \cdot d x \cdot d y
$$

For the mass transfer between the air and the liquid:

$$
G_{a} \cdot d \omega_{a}=h_{D} \cdot\left(\omega_{T s, s a t}-\omega_{a}\right) \cdot a_{w} \cdot L \cdot d x \cdot d y
$$

The enthalpy change of the moist air is given by:

$$
d h_{a}=C_{P a} \cdot d T_{a}+h_{f g} \cdot d \omega_{a}
$$

And the energy balance between the air and the liquid by:

$$
G_{a} \cdot d h_{a}=G_{s} \cdot C_{P s} \cdot d T_{s}+C_{P s} \cdot T_{s} \cdot G_{a} \cdot d \omega_{a}
$$

Finally the mass balance between the air and the liquid gives:

$$
d X_{s}=\frac{G_{a} \cdot d \omega_{a}}{G_{s}-G_{a} \cdot d \omega_{a}} \cdot X_{s}
$$

The $\omega_{T s, s a t}$ is the saturated water content of the air at the surface of the solution and can be

calculated by $\omega_{T s, s a t}=\frac{0.622 \cdot E R H \cdot P_{s}}{P_{a t}-E R H \cdot P_{s}}$

where ERH is the equilibrium relative humidity of the magnesium chloride solution, which is a function of temperature and desiccant's concentration. At temperatures of 20 to $40^{\circ} \mathrm{C}$, it can be expressed only as a function of concentration, from very dilute up to saturation, with an error of $\pm 0.3 \%$ by the following polynomial fit to experimental data reported by Zaytsev and Aseyev (1992):

$$
E R H=-4.7629 \cdot X_{s}^{2}-0.1528 \cdot X_{s}+0.9923
$$

The heat and mass transfer coefficients are calculated based on correlations of Nusselt and Sherwood numbers for cellulose structured pads (Chung et al., 1996).

$$
\begin{aligned}
& N u=2.78 \cdot 10^{-6} \cdot \operatorname{Re}^{1.6} \cdot \operatorname{Pr}^{0.333} \cdot\left(\frac{G_{s}}{G_{a}}\right)^{0.4} \cdot\left(1-X_{s}\right)^{1.8} \\
& S h=2.25 \cdot 10^{-4} \cdot \operatorname{Re} \cdot S c^{0.333} \cdot\left(\frac{G_{s}}{G_{a}}\right)^{0.1} \cdot\left(1-X_{s}\right)^{-0.75}
\end{aligned}
$$

The pad can be divided into an infinite number of differential elements, each with volume $d V, d V=L \cdot d x \cdot d y$ where $L$ is the length of the pad. In this analysis each pad was divided in 100 differential volumes. The enthalpy effectiveness and moisture effectiveness of the dehumidifier describe the combined heat and mass transfer performances and they were calculated by the following equations: 


$$
\begin{gathered}
\eta_{h}=\frac{h_{\mathrm{a}, \text { in }}-h_{\mathrm{a}, \text { out }}}{h_{\mathrm{a}, \text { in }}-h_{\mathrm{e}, \text { in }}} \cdot 100 \% \\
\omega_{h}=\frac{\omega_{\mathrm{a}, \text { in }}-\omega_{\mathrm{a}, \text { out }}}{\omega_{\mathrm{a}, \text { in }}-\omega_{\mathrm{e}, \text { in }}} \cdot 100 \%
\end{gathered}
$$

\section{Experimental Results and Model Predictions}

Table 1 summarizes the results from the preliminary experiments with the system. It is seen that the average percent error between the predicted and the experimental values of mass flow rate of water absorption per unit wetted surface area, $\mathrm{M}_{\mathrm{w}}$, is approximately $13 \%$. There are more significant differences in the case of enthalpy effectiveness than in the case of moisture effectiveness. It is worth noting though that the model presented here does not describe the heat and mass transfer that take place at the surface of the cooling tubes inside the packed column and that in the experiments carried out no cooling was used.

The model was used to predict the air wet bulb temperature drop when passing through the dehumidifier using weather data from Havana, Cuba and Manila, Philippines (average hourly data for whole month obtained from the US Department of Energy). The month chosen was May of year 2005. As seen in Fig. 3, the wet bulb temperature drops were approximately $2.2^{\circ} \mathrm{C}$ and $3^{\circ} \mathrm{C}$ respectively.

\section{CONCLUSIONS}

This study has shown that the proposed heat and mass transfer model for the dehumidifier can be the basis for developing a more accurate model which will incorporate secondary heat and mass transfer processes occurring inside the packed column. We have applied the model in two geographic locations and found that the wet bulb temperature was decreased by $2 \cdot 2-3.0^{\circ} \mathrm{C}$. The results from the preliminary experiments with the constructed liquid desiccant system are promising since it managed to produce a $3.1-3.5^{\circ} \mathrm{C}$ drop without cooling. Further work is needed to be done in optimising the heat and mass transfer model and more experimental data will be required for validation.

\section{ACKNOWLEDGEMENTS}

GL acknowledges financial support from the Greek State Scholarship Foundation.

\section{Literature Cited}

Al-Farayedhi, A.A., Gandhidasan, P., and Al-Mutairi, M.A. 2002. Evaluation of heat and mass transfer coefficients in a gauze-type structured packing air dehumidifier operating with liquid desiccant. International Journal of Refrigeration 25:330-339.

Chung, T.W., Ghosh, T.K., and Hines, A.L. 1996. Comparison between Random and Structured Packings for Dehumidification of Air by Lithium Chloride Solutions in a Packed Column and Their Heat and Mass Transfer Correlations. Ind. Eng. Chem. Res. 35:192-198.

Dai, Y.J., Wang, R.Z., Zhang, H.F., and Yu, J.D. 2001. Use of liquid desiccant cooling to improve the performance of vapor compression air conditioning. Applied Thermal Engineering 21:1185-1202.

Davies, P.A. 2005. A solar cooling system for greenhouse food production in hot climates. Solar Energy 79:661-668. 
Davies, P.A., and Knowles, P.R. 2006. Seawater bitterns as a source of liquid desiccant for use in solar-cooled greenhouses. Desalination 196:266-279.

Gandhidasan, P. 2004. A simplified model for air dehumidification with liquid desiccant. Solar Energy 76:409-416.

Gommed, K., and Grossman, G. 2004. A Liquid Desiccant System for Solar Cooling and Dehumidification. Journal of Solar Energy Engineering 126:879-885.

Jain, S., Dhar, P.L., and Kaushik, S.C. 2000. Experimental studies on the dehumidifier and regenerator of a liquid desiccant cooling system. Applied Thermal Engineering 20:253-267.

Liu, X., Jiang, Y., Xia, J., and Chang, X. 2007a. Analytical solutions of coupled heat and mass transfer processes in liquid desiccant air dehumidifier/regenerator. Energy Conversion and Management 48:2221-2232.

Liu, X.H., Jiang, Y., and Qu, K.Y. 2007b. Heat and mass transfer model of cross flow liquid desiccant air dehumidifier/regenerator. Energy Conversion and Management 48:546-554.

Mei, L., and Dai, Y.J. 2008. A technical review on use of liquid-desiccant dehumidification for air-conditioning application. Renewable and Sustainable Energy Reviews 12:662-689.

Oliveira, A.C., Afonso, C.F., Riffat, S.B., and Doherty, P.S. 2000. Thermal performance of a novel air conditioning system using a liquid desiccant. Applied Thermal Engineering 20:1213-1223.

Stevens, D.I., Braun, J.E., and Klein, S.A. 1989. An effectiveness model of liquiddesiccant system heat/mass exchangers. Solar Energy 42:449-455.

Yin, Y., and Zhang, X. 2008. A new method for determining coupled heat and mass transfer coefficients between air and liquid desiccant. International Journal of Heat and Mass Transfer In Press, Corrected Proof.

Zaytsev, I.D., and Aseyev, G.G. 1992. Properties of aqueous solutions of electrolytes CRC, Boca Raton; London.

\section{Tables}

Table 1. Experimental and predicted results of the preliminary experiments. The volumetric flow was set at $0.0276 \mathrm{~m}^{3} \mathrm{~s}^{-1}$ and the initial mass concentration of the magnesium chloride solution was $34.58 \%$.

\begin{tabular}{ccccc}
\hline & \multicolumn{2}{c}{ 1st run } & \multicolumn{2}{c}{ 2nd run } \\
\cline { 2 - 5 } & Exp. & Pred. & Exp. & Pred. \\
\cline { 2 - 5 } & Air inlet & Air outlet & Air inlet & Air outlet \\
\hline $\mathrm{RH}(\%)$ & 66 & 51 & 72 & 52 \\
$\mathrm{Tdb}\left({ }^{\circ} \mathrm{C}\right)$ & 31.55 & 31.35 & 31.30 & 31.23 \\
$\mathrm{Twb}\left({ }^{\circ} \mathrm{C}\right)$ & 26.33 & 23.43 & 27.07 & 23.50 \\
$\mathrm{Mw}\left(\mathrm{g} \mathrm{h}^{-1} \mathrm{~m}^{-2}\right)$ & 133.5 & 154.8 & 169.2 & 182.5 \\
$\eta_{\mathrm{h}}(\%)$ & 52.8 & 35.4 & 56.8 & 34.1 \\
$\eta_{\mathrm{w}}(\%)$ & 53.8 & 63.0 & 57.8 & 62.9 \\
\hline
\end{tabular}




\section{$\underline{\text { Figures }}$}

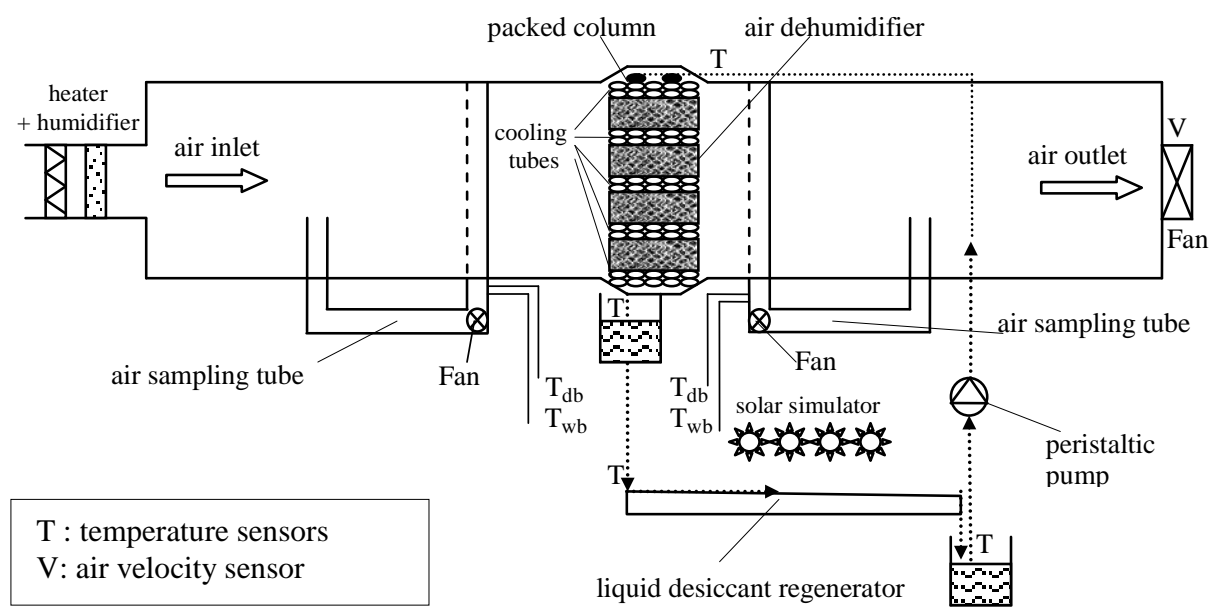

Fig. 1. Schematic diagram of the experimental rig.

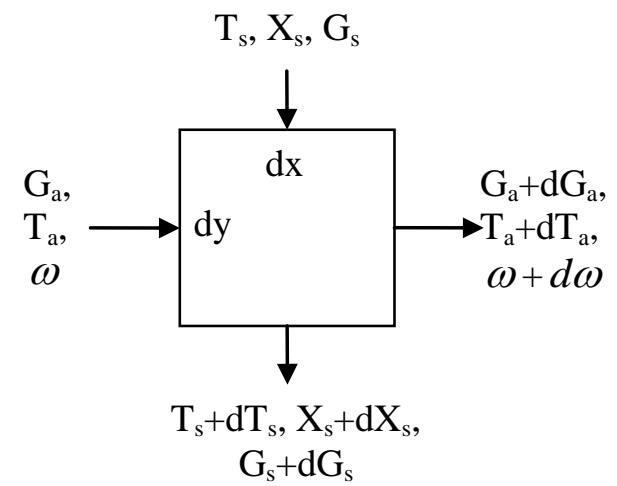

Fig.2. Differential control volume.
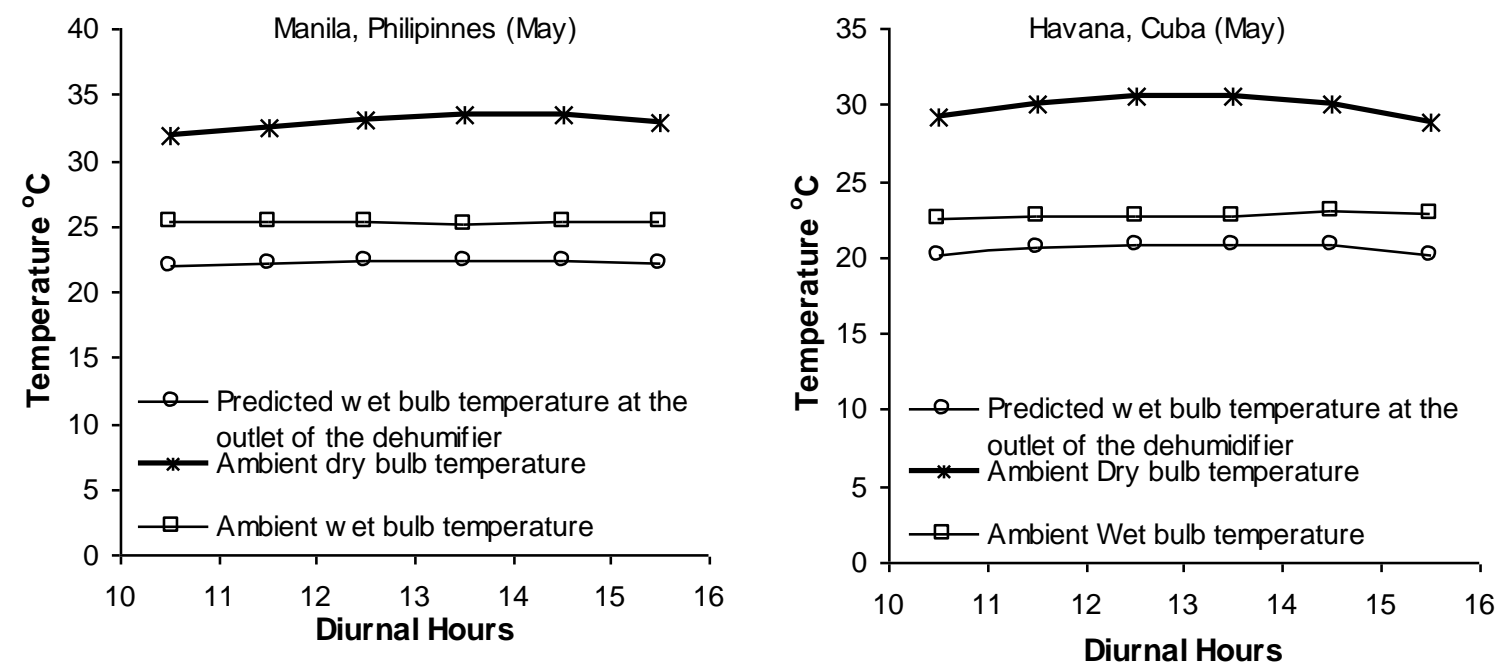

Fig. 3. Wet bulb temperature drop of the air at the outlet of the dehumidifier during 10.00$16.00 \mathrm{hrs}$ in Manila (left) and Havana (right). 


\section{List of Symbols}

\begin{tabular}{|c|c|c|}
\hline & Definition & UNITS \\
\hline$\overline{G_{a}}$ & mass flow of air through a differential volume & $\mathrm{kg} \mathrm{s}^{-1}$ \\
\hline$a_{w}$ & wetted surface per unit volume & $\mathrm{m}^{-1} \mathrm{~m}^{-3}$ \\
\hline$C_{P a}$ & heat capacity of air & $\mathrm{J} \mathrm{kg}^{-1} \mathrm{~K}^{-1}$ \\
\hline$C_{P s}$ & heat capacity of liquid desiccant solution & $\mathrm{J} \mathrm{kg}^{-1} \mathrm{~K}^{-1}$ \\
\hline$T_{a}$ & air temperature & ${ }^{\circ} \mathrm{C}$ or $\mathrm{K}$ \\
\hline$T_{s}$ & solution temperature & ${ }^{\circ} \mathrm{C}$ or $\mathrm{K}$ \\
\hline ERH & equilibrium relative humidity & \\
\hline$G_{s}$ & mass flow of liquid desiccant in a differential volume & $\mathrm{kg} \mathrm{s}^{-1}$ \\
\hline$P_{\text {at }}$ & ambient vapour pressure & $\mathrm{Pa}$ \\
\hline$h_{C}$ & convective heat transfer coefficient & $\mathrm{W} \mathrm{m} \mathrm{m}^{-2} \mathrm{~K}^{-1}$ \\
\hline$h_{D}$ & mass transfer coefficient & $\mathrm{kg} \mathrm{m}^{-2} \mathrm{~s}^{-1}$ \\
\hline$P$ & vapour pressure of the liquid desiccant & $\mathrm{Pa}$ \\
\hline$h_{a}$ & enthalpy of air & $\mathrm{J} \mathrm{kg}^{-1}$ \\
\hline $\begin{array}{l}\mathrm{X}_{\mathrm{s}} \\
\text { Greek variables }\end{array}$ & mass concentration of desiccant solution & $\%$ \\
\hline$\eta_{h}$ & enthalpy effectiveness & $\%$ \\
\hline$\eta_{w}$ & moisture effectiveness & $\%$ \\
\hline$\omega_{a}$ & water content of the air & $\mathrm{kg} / \mathrm{kg}$ \\
\hline$\omega_{T s, s a t}$ & $\begin{array}{l}\text { water content of the air in equilibrium with the } \\
\text { desiccant solution }\end{array}$ & $\mathrm{kg} / \mathrm{kg}$ \\
\hline
\end{tabular}

